\title{
Clinical Risk Factors for Portopulmonary Hypertension
}

\author{
Steven M. Kawut ${ }^{1,2}$, Michael J. Krowka ${ }^{3}$, James F. Trotter ${ }^{4}$, Kari E. Roberts ${ }^{5}$, Raymond L. \\ Benza $^{6}$, David B. Badesch ${ }^{4}$, Darren B. Taichman ${ }^{7}$, Evelyn M. Horn ${ }^{1}$, Steven Zacks ${ }^{8}$, Neil \\ Kaplowitz ${ }^{9}$, Robert S. Brown $\mathrm{Jr}^{1}$, Michael B. Fallon ${ }^{6}$, and Pulmonary Vascular \\ Complications of Liver Disease Study Group \\ ${ }^{1}$ Department of Medicine, College of Physicians and Surgeons, Joseph L. Mailman School of \\ Public Health, Columbia University, New York, NY \\ 2Department of Epidemiology, Joseph L. Mailman School of Public Health, Columbia University, \\ New York, NY \\ ${ }^{3}$ Department of Medicine, Mayo Clinic, Rochester, MN \\ ${ }^{4}$ Department of Medicine, University of Colorado, Denver, CO \\ ${ }^{5}$ Department of Medicine, Tufts-New England Medical Center, Boston, MA \\ ${ }^{6}$ Department of Medicine, University of Alabama, Birmingham, AL \\ ${ }^{7}$ Department of Medicine, University of Pennsylvania, Philadelphia, PA \\ ${ }^{8}$ Department of Medicine, The University of North Carolina at Chapel Hill, Chapel Hill, NC \\ ${ }^{9}$ Department of Medicine, University of Southern California, Los Angeles, CA
}

\section{Abstract}

\begin{abstract}
Portopulmonary hypertension affects up to $6 \%$ of patients with advanced liver disease, but the predictors and biologic mechanism for the development of this complication are unknown. We sought to determine the clinical risk factors for portopulmonary hypertension in patients with advanced liver disease. We performed a multicenter case-control study nested within a prospective cohort of patients with portal hypertension recruited from tertiary care centers. Cases had a mean pulmonary artery pressure $>25 \mathrm{~mm} \mathrm{Hg}$, pulmonary vascular resistance $>240$ dynes $\cdot$ second · $\mathrm{cm}^{-5}$, and pulmonary capillary wedge pressure $\leq 15 \mathrm{~mm} \mathrm{Hg}$. Controls had a right ventricular systolic pressure $<40 \mathrm{~mm} \mathrm{Hg}$ (if estimable) and normal right-sided cardiac morphology by transthoracic echocardiography. The study sample included 34 cases and 141 controls. Female sex was associated with a higher risk of portopulmonary hypertension than male sex (adjusted odds ratio $=2.90,95 \%$ confidence interval $1.20-7.01, P=0.018$ ). Autoimmune hepatitis was associated with an increased risk (adjusted odds ratio $=4.02,95 \%$ confidence interval $1.14-14.23, P=0.031$ ),
\end{abstract}

Copyright (C 2008 by the American Association for the Study of Liver Diseases.

Address reprint requests to: Steven Kawut, M.D., M.S., Division of Pulmonary, Allergy, and Critical Care Medicine, Columbia University College of Physicians and Surgeons, 622 West 168th Street, PH 8E, Room 101, New York, NY 10032. sk2097@ columbia.edu; fax: 212-342-5382.

Potential conflict of interest: Dr. Taichman received grants from Actelion. Dr. Trotter received grants from Roche, Debivision, and Wyeth. He is on the speakers' bureau of Salix and Astellis. He consults for and received grants from Novartis. Dr. Kawut is a consultant for Encysive. He is a consultant for, advises, is on the speakers' bureau of, and received grants from Gilead. He is on the speakers' bureau of and received grants from Pfizer and Actelion. He is a consultant for and received grants from United Therapeutics. $\mathrm{He}$ is on the speakers' bureau of INO Therapeutics. He received grants from Lung Rx. Dr. Badesch is a consultant for, is on the speakers' bureau of, advises, and received grants from GlaxoSmithKline, United Therapeutics/Lung Rx, Actelion/CoTehrix, Encysive, Pfizer, and Gilead/Myogen. He also received grants from Lilly/ICOS. He is a consultant for and advises Mondo-Biotech and Biogen IDEC.

Published online in Wiley InterScience (www.interscience.wiley.com). 
and hepatitis $\mathrm{C}$ infection was associated with a decreased risk (adjusted odds ratio $=0.24,95 \%$ confidence interval 0.09-0.65, $P=0.005$ ) of portopulmonary hypertension. The severity of liver disease was not related to the risk of portopulmonary hypertension.

Conclusion-Female sex and autoimmune hepatitis were associated with an increased risk of portopulmonary hypertension, whereas hepatitis $\mathrm{C}$ infection was associated with a decreased risk in patients with advanced liver disease. Hormonal and immunologic factors may therefore be integral to the development of portopulmonary hypertension.

Pulmonary arterial hypertension (PAH) is a progressive disease which is characterized by elevated pulmonary vascular resistance, right heart failure, exercise limitation, and an increased risk of death. Histopathologic examination reveals intimal proliferation, medial hypertrophy, and adventitial fibrosis in the small muscular pulmonary arteries. Plexiform lesions and in situ thrombosis are also commonly seen. Most commonly idiopathic, PAH may also be associated with portal hypertension, termed portopulmonary hypertension (PPHTN). McDonnell et al. showed a prevalence of histopathologic changes of PAH in $0.61 \%$ of autopsies of patients with cirrhosis, and PPHTN was the third most common form of PAH in a population-based epidemiologic study in France. ${ }^{1,2}$ Recent cohort studies showed a prevalence of PPHTN of 5\%-6\% in patients presenting for liver transplant evaluation. ${ }^{3-5}$ Patients with PPHTN have an increased risk of death, even with specific PAH treatment. ${ }^{4,6}$ In many cases, PPHTN greatly complicates or precludes liver transplantation, significantly affecting the course of hepatic failure in these patients. ${ }^{7,8}$

There are no known clinical factors which determine the risk of PPHTN in patients with advanced liver disease. Similarly, the mechanism for pulmonary vascular obliteration in patients with portal hypertension (characterized by systemic vasodilation) is unknown. It follows that the identification of patient characteristics that increase or decrease the probability of developing PPHTN might not only be clinically useful, but could also shed light on the etiology of this relatively common comorbidity of portal hypertension. Therefore, we studied whether demographics, type and severity of underlying liver disease, or other patient factors were associated with the risk of PPHTN.

\section{Patients and Methods}

\section{Study Design and Study Sample}

The Pulmonary Vascular Complications of Liver Disease (PVCLD) Study prospectively enrolled a cohort of 536 patients evaluated for liver transplantation or pulmonary hypertension at seven centers in the United States between 2003 and 2006. The only inclusion criterion was the presence of clinical portal hypertension with or without intrinsic liver disease. We excluded patients with evidence of active infection or recent (less than 2 weeks) gastrointestinal bleeding, or who had undergone liver or lung transplantation.

Patients in the prospective cohort were newly referred for evaluation for liver transplantation or pulmonary hypertension. We also included patients in the cohort who had been diagnosed with PPHTN and treated before the beginning of the study ("prevalent" patients).

We performed a case-control study nested within the prospectively-assembled PVCLD cohort. The study sample included newly referred patients who were evaluated with transthoracic echocardiography (routinely performed for pretransplant evaluation) during the study period. "Prevalent" patients who met the case definition (see below) were also included. We excluded patients with significant obstructive lung disease, defined as forced expiratory volume in 1 second (FEV1)/forced vital capacity (FVC) $<0.70$ with FEV1 percent predicted $<80 \%$, and patients with a significant restrictive ventilatory defect, defined as FVC percent predicted and (if performed) total lung capacity percent predicted $<70 \%$. Patients 
who otherwise fulfilled the case definition (see below) without available pulmonary function testing were included if chest radiography showed neither significant hyperinflation nor interstitial lung disease; controls without pulmonary function testing were excluded. The study sample also excluded patients with human immunodeficiency virus infection or the presence of more than moderate aortic or mitral stenosis or regurgitation or significant left ventricular dysfunction determined by transthoracic echocardiography.

\section{Case and Control Definitions}

Cases with PPHTN met the following criteria at initial evalution: (1) mean pulmonary artery pressure $>25 \mathrm{~mm} \mathrm{Hg}$, pulmonary capillary wedge pressure (or left ventricular end-diastolic pressure) $\leq 15 \mathrm{~mm} \mathrm{Hg}$, and pulmonary vascular resistance $>240$ dynes $\cdot$ second $\cdot \mathrm{cm}^{-5}$ measured by right heart catheterization, and (2) no other etiology for pulmonary hypertension. Controls met the following echocardiographic criteria at entry into the cohort: (1) right ventricular (RV) systolic pressure $<40 \mathrm{~mm} \mathrm{Hg}$ (if estimable) and (2) absence of right atrial or ventricular dilation, hypertrophy, or dysfunction. Data from the initial evaluation (before treatment) were used in analysis of "prevalent" cases. It was recommended that right heart catheterization should be performed for patients with RV systolic pressure $>50 \mathrm{~mm} \mathrm{Hg}$ with abnormal RV morphology by echocardiography.

Sensitivity analyses included both patients who met the case definition but who had pulmonary capillary wedge pressure between 16 and $19 \mathrm{~mm} \mathrm{Hg}$ as cases and patients who met the control definition but who had abnormal right atrial or ventricular morphology and/ or RV systolic pressure $<50 \mathrm{~mm} \mathrm{Hg}$ (if estimable) as controls. We also performed a subset analysis with cases who presented for their initial evaluation during the study period.

\section{Potential Predictors}

Data were collected from the patients and from the medical record. The etiology of underlying liver disease (or portal vein thrombosis), past medical history, and social history were recorded. Patients underwent a physical examination that included anthropometry, blood pressure measurements, and laboratory assessment. The Model for End-Stage Liver Disease (MELD) score was calculated. ${ }^{9}$

\section{Other Variables}

Chest radiography and computed tomography were interpreted locally at each center. The results of the abdominal imaging study closest to the day of initial evaluation (computed tomography, magnetic resonance imaging, or ultrasound) were recorded. Spirometry, lung volumes, and diffusing capacity for carbon monoxide were measured; results are expressed using standard sex-specific and race-specific prediction equations, where appropriate. ${ }^{10-12}$ Arterial blood gas was obtained, and the alveolar-arterial oxygen gradient was calculated. Transthoracic echocardiography was interpreted at each center. Injection of agitated saline was performed through a peripheral vein; an intrapulmonary shunt was considered present if appearance of micro-bubbles in the left atrium occurred three or more cardiac cycles after opacification of the right side of the heart. The study was approved by the Institutional Review Board of each center, and patients provided informed consent before undergoing study procedures.

\section{Statistical Analyses}

Continuous data were summarized using mean \pm standard deviation or median (interquartile range), as appropriate. Categorical variables were summarized using n (\%). Bivariate logistic regression was performed with case/control status as the dependent variable and potential predictors as independent variables with results expressed as odds ratios (ORs). 
Multivariate logistic regression was performed including all variables which had $P$ value < 0.20 on bivariate analysis or were hypothesized to predict case status. With the number of cases, we determined that the final multivariate model should include four or fewer predictors to prevent overfitting. Unpaired Student $t$ tests, Wilcoxon rank sum tests, chisquared tests, and Fisher's exact tests were used for other analyses, as appropriate.

The final multivariate model was assessed using the Hosmer-Lemeshow goodness-of-fit test; dbetas were calculated to assess for influential subjects. All analyses were performed with available data without imputation using Stata/IC version 10.0 (StataCorp, College Park, TX). A two-sided $P$ value of $<0.05$ was considered statistically significant.

\section{Results}

There were 34 cases and 141 controls in the study sample. The mean age of the patients was $53 \pm 9$ years, and $44 \%$ were female. A total of $76 \%$ were non-Hispanic white, $13 \%$ were Hispanic white, and 5\% were non-Hispanic black. Patients with PPHTN had a mean right atrial pressure of $10 \pm 7 \mathrm{~mm} \mathrm{Hg}$, a mean pulmonary artery pressure of $49 \pm 9 \mathrm{~mm} \mathrm{Hg}$, and pulmonary capillary wedge pressure (or left ventricular end-diastolic pressure) of $10 \pm 3 \mathrm{~mm}$ $\mathrm{Hg}$ by right heart catheterization. The mean cardiac output was $5.4 \pm 1.8 \mathrm{~L} /$ minute, the cardiac index was $2.8 \pm 0.9 \mathrm{~L} /$ minute $/ \mathrm{m}^{2}$, and the pulmonary vascular resistance was $696 \pm$ 397 dynes $\cdot$ second $\cdot \mathrm{cm}^{-5}$. Mean pulmonary artery oxygen saturation was $65 \pm 11 \%(\mathrm{~N}=$ $31)$.

\section{Bivariate Analyses}

Cases and controls were similar in terms of age and race/ethnicity (Table 1). Cases with PPHTN were significantly more likely to be female than liver disease controls $(\mathrm{OR}=3.98$, $95 \%$ confidence interval 1.77-8.98, $P=0.001$ ). Almost half of the cases and controls had liver disease attributable to alcohol use. Cases with PPHTN were significantly less likely than liver disease controls to be infected with hepatitis $C$, whereas they were significantly more likely to have autoimmune hepatitis (both $P \leq 0.001$ ). Patients with PPHTN were also somewhat more likely to have primary biliary cirrhosis than controls, however, this was not statistically significant. There was no association between case/control status and the prevalence of nonalcoholic fatty liver disease, hepatitis B infection, primary sclerosing cholangitis, or cryptogenic cirrhosis. There were fewer than three patients in each group with primary portal vein thrombosis (one case), alpha-1 antitrypsin deficiency (one case, two controls), biliary atresia (one control), or sarcoid (one case). Patients in the study sample may have had more than one etiology of liver disease. One patient with PPHTN (3\%) was receiving interferon therapy as were five $(4 \%)$ liver disease controls $(P=1.0)$.

The median time from diagnosis of the underlying liver disease to evaluation at the study center was 6 years for cases and 3 years for controls $(P=0.04, \mathrm{~N}=162)$. The mean MELD score was $12 \pm 4$ and $13 \pm 5$ in cases and controls, respectively $(P=0.81)$. A total of $34 \%$ of PPHTN cases and $36 \%$ of controls had mild liver disease (MELD score $\leq 10$ ), and there was no association between the presence of mild liver disease and PPHTN case status $(P=1.0)$. Similarly, there were no associations between mean pulmonary artery pressure or pulmonary vascular resistance and age, sex, or MELD score in patients with PPHTN (data not shown).

Cases with PPHTN were less likely than liver disease controls to have a history of ascites and possibly less likely to have a history of encephalopathy, but there were no differences between the groups in terms of other complications of liver disease or portal hypertension (Table 2). A transjugular intrahepatic portosystemic shunt (or surgical shunt) was placed in $3 \%$ of cases and $6 \%$ of controls $(P=0.53)$ The prevalence of chronic obstructive pulmonary disease, diabetes mellitus, hypertension and other medical conditions were similar between 
the groups. Most cases and controls had a history of smoking and chronic alcohol use, whereas controls were somewhat more likely than cases to have used intravenous drugs.

There were no differences between cases and controls in terms of vital signs and signs of portal hypertension and hepatic dysfunction by physical examination, other than there being a lower probability of ascites in patients with PPHTN (Table 3). Hemoglobin was slightly higher in cases than controls. However, white blood cell count, platelet count, and the international normalized ratio were similar. There were no differences in total bilirubin or total protein, although cases had a higher mean serum albumin and lower aminotransferase levels compared to controls.

Chest radiography showed cardiomegaly and large pulmonary arteries more commonly in the patients with PPHTN than in liver disease controls (Table 4). There were no differences in spirometric measures between cases and controls; however, cases had lower diffusing capacity for carbon monoxide (corrected for hemoglobin) percent predicted. Cases had slightly higher arterial $\mathrm{pH}$, lower arterial partial pressure of oxygen, and higher alveolararterial oxygen gradient. Abdominal imaging confirmed a lower prevalence of ascites in cases compared to controls; most patients in both groups had splenomegaly.

Patients with PPHTN had characteristic right-sided findings on transthoracic echocardiography; liver disease controls (by definition) did not show right-sided abnormalities (Table 5). Cases had somewhat more left ventricular hypertrophy, however, left atrial size was similar between the groups. Pericardial effusion was more common in patients with PPHTN (22\%) compared to liver disease controls $(6 \%)(P=0.011)$. Intrapulmonary shunting was significantly less common in cases (30\%) than in controls $(56 \%)(P=0.02)$.

\section{Multivariate Analysis}

We assessed the variables from Tables 1 and 2 in multivariate logistic regression (Table 6). Female sex and autoimmune hepatitis were independently associated with an increased risk of PPHTN. On the other hand, hepatitis $C$ infection was associated with a lower risk of PPHTN. Other demographics, anthropomorphics, MELD score, and medical comorbidities were not significant predictors in the multivariate model. Model fit was adequate by the Hosmer-Lemeshow goodness-of-fit test $(P=0.62)$, and there were no overly influential subjects.

An analysis incorporating patients who met the criteria for PPHTN except for having a pulmonary capillary wedge pressure between 16 and $19 \mathrm{~mm} \mathrm{Hg}(\mathrm{N}=3)$ showed similar results. Inclusion of patients with abnormal right-sided echocardiographic results as controls similarly did not alter the conclusions. A subset analysis excluding "prevalent" case patients $(\mathrm{N}=15)$ produced results consistent with the final logistic model.

\section{Discussion}

This is the first multicenter epidemiologic study of the clinical risk factors for PPHTN in patients with severe liver disease and portal hypertension. Using a case-control design (wellsuited to study this rare disease), we have demonstrated that females with liver disease have a higher risk than males of developing PPHTN. We have also shown that the etiology of liver disease is important in determining the risk of this serious pulmonary vascular complication. Patients with autoimmune hepatitis have a higher risk and patients with hepatitis $\mathrm{C}$ infection have a lower risk of PPHTN than patients with other etiologies of liver disease. Previously hypothesized factors, such as age, severity of liver disease, and medical comorbidities, were not associated with the risk of PPHTN. Patients with PPHTN also had 
characteristic radiographic, arterial blood gas, and echocardiographic findings and were less likely than controls to have intrapulmonary shunting.

The idiopathic and familial forms of PAH are well-known to occur more commonly in women than in men. ${ }^{13,14}$ However, this is the first form of PAH related to an associated condition shown to have an increased risk in women compared to men. Although PAH associated with connective tissue disease frequently occurs in women, such diseases are as a whole more common in women, and sex is not thought to affect the risk of PAH in this setting. ${ }^{15}$ Prior retrospective studies of PPHTN have shown a possible overrepresentation of women compared to men (considering the underlying demographic of portal hypertension), but the absence of appropriate control groups has prevented a definitive statement until this point. ${ }^{5,16}$ For example, Krowka et al. compared patients with PPHTN to liver disease patients with pulmonary hypertension by echocardiography which did not meet the criteria for PPHTN. These authors found no significant differences in demographics or other variables between these two groups of patients. The discrepancy between these authors' conclusions and ours is likely explained by differences between the control group in the study of Krowka et al. (patients with liver disease with pulmonary hypertension determined by echocardiography) and the control group of our study (patients with liver disease with normal right heart morphology determined by echocardiography).

Hormone profile, pregnancy, and a tendency toward autoimmune processes are three mechanistic factors which may explain the female sex predilection for PAH. Interestingly, the female sex predominance in our study was independent of the underlying etiology of liver disease, indicating that this finding was not accounted for by a predisposition to autoimmune liver disease. These findings indicate that the biologic components of sex differences may be an important starting point from which to understand why patients with liver disease develop PPHTN.

Several lines of investigation have suggested that PAH has an immune etiology. First, individuals with certain human leukocyte antigen subtypes have a higher risk of PAH than do those with other subtypes. ${ }^{17,18}$ Second, connective tissue diseases are a well-established risk factor for PAH. Third, antinuclear antibody titers are frequently elevated in patients with PAH. ${ }^{19,20}$ Last, immune-mediated diseases of other organs (for example, thyroid) are common in patients with $\mathrm{PAH} .{ }^{21} \mathrm{We}$ found that autoimmune hepatitis (and possibly primary biliary cirrhosis) was associated with an increased risk of PPHTN. Therefore, in some cases, PPHTN may be attributable not only to the presence of portal hypertension, but also to the autoimmune process resulting in liver disease, consistent with a "two-hit" hypothesis.

Patients with hepatitis C infection were less likely to suffer from PPHTN, even after consideration of the demographics and medical and social histories of these patients. There may be some characteristic of the treatment for hepatitis $\mathrm{C}$-associated liver disease which decreases the risk in this population. However, we did not find differences between cases and controls in the use of interferon at the time of evaluation, although we did not have available data on all treatments received previously. Alternatively, there could be a direct effect of the virus which is protective to the pulmonary vasculature. The basis of this novel association is unknown.

The American Association for the Study of Liver Diseases currently recommends that all patients being evaluated for liver transplantation undergo screening with transthoracic echocardiography, due to the greatly increased perioperative risk of death for a liver transplant recipient with untreated PPHTN. ${ }^{22}$ However, it is not established whether patients with liver disease who are not transplant candidates warrant screening for this condition. Given the relatively low specificity of echocardiography (that is, high false-positive rate) 
and the lack of well-studied therapies for PPHTN with documented efficacy, ${ }^{23-25}$ it is likely premature to recommend screening for patients with liver disease who are not transplant candidates, even if they fall into the "high-risk" subgroups in our study. On the other hand, clinicians should have a low threshold to obtain echocardiography in patients with portal hypertension with symptoms suggestive of PPHTN.

Certain factors that have been postulated to be linked to PPHTN were not associated with case status in our study. Age and race/ethnicity did not differ between the groups. Cases with PPHTN (which included prevalent patients) may have had a longer duration of liver disease, however, there were no differences between cases and controls in terms of severity of liver disease (that is, MELD score and previous hepatic complications, except for ascites and encephalopathy). The placement of a portosystemic shunt or performance of splenectomy did not affect the risk of PPTHN. Smoking and chronic alcohol use were common in both groups.

Levels of liver aminotransferases were somewhat lower in cases than in controls, and albumin levels were higher. However, other markers of liver function were similar between the groups. These differences possibly reflect the different types of liver disease represented in the two populations. The lower diffusing capacity for carbon monoxide, acid-base abnormalities, and higher alveolar-arterial oxygen gradient in the absence of significant differences in spirometric measures confirm other studies which have shown these abnormalities in patients with PPHTN. ${ }^{26}$ These findings likely result from the vascular arteriopathy and ventilation:perfusion mismatch which characterize PAH.

Patients with PPHTN had pericardial effusions more commonly than did controls. The presence of a pericardial effusion is associated with worse survival in idiopathic $\mathrm{PAH}^{20,27}$; the clinical implications of a pericardial effusion in PPHTN are unknown. Intrapulmonary shunting was less common (although still relatively frequent) in cases with PPHTN than in the liver disease controls. Pulmonary vasodilation is common in patients with advanced liver disease and portal hypertension, and when accompanied by abnormal arterial partial pressure of oxygen, defines hepatopulmonary syndrome. Considering the hemodynamic profile of PPHTN, less pulmonary vasodilation would be expected in these patients; however, the relationship of these two opposing pulmonary vascular syndromes seen in the setting of portal hypertension remains to be clarified.

There are some limitations to our study. This is one of the largest samples of patients with PPHTN with detailed phenotyping ever collected; however, there was a relatively small number of cases. The predictors we describe had large effect sizes and were highly significant, and our final multivariate model was robust to alterations in case and control definitions, deletion of potentially influential subjects, and exclusion of prevalent subjects. It is however possible that risk factors with smaller effect sizes may not have been detected in our study. Information bias is possible, but we used standard data collection forms for all patients. Although this could still be a problem (because some data were collected after case/ control status was established), the predictors in our final model (that is, sex and liver disease diagnosis) are not easily affected by such bias. We specifically avoided inclusion of factors which could be affected by PPHTN, such as radiographic and laboratory findings, in our final explanatory multivariate model. Selection bias and exchangeability are always a concern in case-control studies. However, it would appear that the liver disease controls at each center came from the same source population as the cases by design, and the severity of liver disease (reflected by MELD) was virtually identical between the groups, assuring the comparability of the two groups. Echocardiography and right heart catheterization results were interpreted locally; measurement error and misclassification are possible. However, such misclassification would have led to bias to the null, unless such error was systematic 
and related to the risk factors demonstrated, which was unlikely. We recorded a variety of potential risk factors for PPHTN; nonetheless, our findings could be accounted for by another confounding variable or residual confounding.

In summary, sex and type of liver disease affect the risk of PPHTN. These are the first clinical predictors of PPHTN ever defined. The mechanistic role of these factors in the evolution of PPHTN in patients with portal hypertension should be examined in future studies.

\section{Appendix}

The Pulmonary Vascular Complications of Liver Disease Study Group also includes: Columbia University: Jenna Reinen, BA, Jeffrey Okun, BA, Daniel Rabinowitz, PhD, Debbie Rybak, BA; Mayo Clinic: Linda Stadheim, RN, Vijay Shah, MD, Russell Wiesner, MD; University of Alabama: Dottie Faulk, J. Stevenson Bynon, MD, Devin Eckhoff, MD, Harpreet Singh, Rajasekhar Tanikella; University of Colorado: Ted Perry, Lisa Forman, MD; The University of North Carolina at Chapel Hill: Carrie Nielsen, RN, Roshan Shrestha, MD; University of Pennsylvania: Vivek Ahya, MD, Harold Palevsky, MD, Rajender Reddy, MD; University of Southern California: James Knowles, MD, PhD.

\section{Acknowledgments}

Funded by National Institutes of Health grants DK064103, DK065958, RR00645, RR00585, RR00046, RR00032, and HL67771.

\section{References}

1. Humbert M, Sitbon O, Chaouat A, Bertocchi M, Habib G, Gressin V, et al. Pulmonary arterial hypertension in France: results from a national registry. Am J Respir Crit Care Med 2006;173:1023-1030. [PubMed: 16456139]

2. McDonnell PJ, Toye PA, Hutchins GM. Primary pulmonary hypertension and cirrhosis: are they related? Am Rev Respir Dis 1983;127:437-441. [PubMed: 6838050]

3. Colle IO, Moreau R, Godinho E, Belghiti J, Ettori F, Cohen-Solal A, et al. Diagnosis of portopulmonary hypertension in candidates for liver transplantation: a prospective study. Hepatology 2003;37:401-409. [PubMed: 12540791]

4. Kawut SM, Taichman DB, Ahya VN, Kaplan S, Archer-Chicko CL, Kimmel SE, et al. Hemodynamics and survival of patients with portopulmonary hypertension. Liver Transpl 2005;11:1107-1111. [PubMed: 16123953]

5. Krowka MJ, Swanson KL, Frantz RP, McGoon MD, Wiesner RH. Portopulmonary hypertension: Results from a 10-year screening algorithm. Hepatology 2006;44:1502-1510. [PubMed: 17133488]

6. Herve P, Le Pavec J, Sztrymf B, Decante B, Savale L, Sitbon O. Pulmonary vascular abnormalities in cirrhosis. Best Pract Res Clin Gastroenterol 2007;21:141-159. [PubMed: 17223502]

7. Sussman N, Kaza V, Barshes N, Stribling R, Goss J, O’Mahony C, et al. Successful liver transplantation following medical management of portopulmonary hypertension: a single-center series. Am J Transplant 2006;6:2177-2182. [PubMed: 16796721]

8. Krowka MJ, Mandell MS, Ramsay MA, Kawut SM, Fallon MB, Manzarbeitia C, et al. Hepatopulmonary syndrome and portopulmonary hypertension: a report of the multicenter liver transplant database. Liver Transpl 2004;10:174-182. [PubMed: 14762853]

9. Kamath PS, Wiesner RH, Malinchoc M, Kremers W, Therneau TM, Kosberg CL, et al. A model to predict survival in patients with end-stage liver disease. Hepatology 2001;33:464-470. [PubMed: 11172350]

10. Crapo RO, Morris AH. Standardized single breath normal values for carbon monoxide diffusing capacity. Am Rev Respir Dis 1981;123:185-189. [PubMed: 7235357] 
11. Crapo RO, Morris AH, Clayton PD, Nixon CR. Lung volumes in healthy nonsmoking adults. Bull Eur Physiopathol Respir 1982;18:419-425. [PubMed: 7074238]

12. Hankinson JL, Odencrantz JR, Fedan KB. Spirometric reference values from a sample of the general U.S. population. Am J Respir Crit Care Med 1999;159:179-187. [PubMed: 9872837]

13. Loyd JE, Butler MG, Foroud TM, Conneally PM, Phillips JA 3rd, Newman JH. Genetic anticipation and abnormal gender ratio at birth in familial primary pulmonary hypertension. Am J Respir Crit Care Med 1995;152:93-97. [PubMed: 7599869]

14. Loyd JE, Primm RK, Newman JH. Familial primary pulmonary hypertension: clinical patterns. Am Rev Respir Dis 1984;129:194-197. [PubMed: 6703480]

15. Hachulla E, Gressin V, Guillevin L, Carpentier P, Diot E, Sibilia J, et al. Early detection of pulmonary arterial hypertension in systemic sclerosis: a French nationwide prospective multicenter study. Arthritis Rheum 2005;52:3792-3800. [PubMed: 16320330]

16. Herve P, Lebrec D, Brenot F, Simonneau G, Humbert M, Sitbon O, et al. Pulmonary vascular disorders in portal hypertension. Eur Respir J 1998;11:1153-1166. [PubMed: 9648972]

17. Morse JH, Barst RJ, Fotino M, Zhang Y, Flaster E, Gharavi AE, et al. Primary pulmonary hypertension, tissue plasminogen activator antibodies, and HLA-DQ7. Am J Respir Crit Care Med 1997;155:274-278. [PubMed: 9001324]

18. Morse JH, Barst RJ, Itescu S, Flaster ER, Sinha G, Zhang Y, et al. Primary pulmonary hypertension in HIV infection: an outcome determined by particular HLA class II alleles. Am J Respir Crit Care Med 1996;153:1299-1301. [PubMed: 8616557]

19. Isern RA, Yaneva M, Weiner E, Parke A, Rothfield N, Dantzker D, et al. Autoantibodies in patients with primary pulmonary hypertension: association with anti-Ku. Am J Med 1992;93:307312. [PubMed: 1524083]

20. Kawut SM, Horn EM, Berekashvili KK, Garofano RP, Goldsmith RL, Widlitz AC, et al. New predictors of outcome in idiopathic pulmonary arterial hypertension. Am J Cardiol 2005;95:199203. [PubMed: 15642552]

21. Chu JW, Kao PN, Faul JL, Doyle RL. High prevalence of autoimmune thyroid disease in pulmonary arterial hypertension. Chest 2002;122:1668-1673. [PubMed: 12426269]

22. Murray KF, Carithers RL Jr. AASLD practice guidelines: Evaluation of the patient for liver transplantation. Hepatology 2005;41:1407-1432. [PubMed: 15880505]

23. Fix OK, Bass NM, De Marco T, Merriman RB. Long-term follow-up of portopulmonary hypertension: effect of treatment with epoprostenol. Liver Transpl 2007;13:875-885. [PubMed: 17539008]

24. Hoeper MM, Seyfarth HJ, Hoeffken G, Wirtz H, Spiekerkoetter E, Pletz MW, et al. Experience with inhaled iloprost and bosentan in portopulmonary hypertension. Eur Respir J 2007;30:10961102. [PubMed: 17652314]

25. Kawut SM. Caring for the orphan's orphan: treatment of patients with portopulmonary hypertension. Eur Respir J 2007;30:1038-1040. [PubMed: 18055701]

26. Kuo PC, Plotkin JS, Johnson LB, Howell CD, Laurin JM, Bartlett ST, et al. Distinctive clinical features of portopulmonary hypertension. Chest 1997;112:980-986. [PubMed: 9377962]

27. Raymond RJ, Hinderliter AL, Willis PW, Ralph D, Caldwell EJ, Williams W, et al. Echocardiographic predictors of adverse outcomes in primary pulmonary hypertension. J Am Coll Cardiol 2002;39:1214-1219. [PubMed: 11923049]

\section{Abbreviations}

$\begin{array}{ll}\text { FEV1 } & \text { forced expiratory volume in one second } \\ \text { FVC } & \text { forced vital capacity } \\ \text { MELD } & \text { Model for End-Stage Liver Disease } \\ \text { OR } & \text { odds ratio } \\ \text { PAH } & \text { pulmonary arterial hypertension }\end{array}$




$\begin{array}{ll}\text { PPHTN } & \text { portopulmonary hypertension } \\ \text { PVCLD } & \text { Pulmonary Vascular Complications of Liver Disease } \\ \text { RV } & \text { right ventricular }\end{array}$


Table 3

Physical Examination and Laboratory Results

\begin{tabular}{lcccc}
\hline Variable & $\mathbf{N}$ & Cases & Controls & P Value \\
\hline Physical examination & & & & \\
Body mass index, kg/m & 175 & $29 \pm 5$ & $28 \pm 6$ & 0.78 \\
Pulse, beats per minute & 175 & $78 \pm 15$ & $75 \pm 12$ & 0.22 \\
Systolic blood pressure, mm Hg & 173 & $115 \pm 17$ & $119 \pm 17$ & 0.23 \\
Diastolic blood pressure, mm Hg & 173 & $68 \pm 9$ & $70 \pm 11$ & 0.34 \\
Room air oxygen saturation, \% & 158 & $95 \pm 4$ & $95 \pm 3$ & 0.30 \\
Ascites & 172 & $5(16 \%)$ & $55(39 \%)$ & 0.01 \\
Lower extremity edema & 174 & $18(53 \%)$ & $67(48 \%)$ & 0.60 \\
Clubbing & 172 & $1(3 \%)$ & $9(7 \%)$ & 0.69 \\
Asterixis & 173 & $2(6 \%)$ & $3(2 \%)$ & 0.25 \\
Spider angiomata & 168 & $7(21 \%)$ & $39(29 \%)$ & 0.38 \\
Laboratory results & & & & \\
Blood urea nitrogen, mg/dL & 173 & $14[10-19]$ & $14[10-18]$ & 0.95 \\
Creatinine, mg/dL & 174 & $0.9[0.8-1.1]$ & $0.9[0.7-1.1]$ & 0.78 \\
Hemoglobin, g/dL & 173 & $14 \pm 2$ & $13 \pm 2$ & 0.05 \\
Platelet count, 109/L & 170 & $82[66-103]$ & $90[67-137]$ & 0.19 \\
International normalized ratio & 174 & $1.3[1.2-1.4]$ & $1.2[1.1-1.4]$ & 0.49 \\
Alanine aminotransferase, U/L & 174 & $28[23-54]$ & $49[31-79]$ & 0.002 \\
Aspartate aminotransferase, U/L & 174 & $44[35-61]$ & $74[47-110]$ & $<0.001$ \\
Total bilirubin, mg/dL & 174 & $1.8[1.1-2.7]$ & $1.9[1.3-2.9]$ & 0.67 \\
Alkaline phosphatase, U/L & 172 & $114[96-164]$ & $140[100-203]$ & 0.045 \\
Total protein, g/dL & 165 & $7.3 \pm 0.8$ & $7.2 \pm 0.9$ & 0.28 \\
Albumin, g/dL & 167 & $3.7 \pm 0.4$ & $3.2 \pm 0.7$ & $<0.001$ \\
\hline
\end{tabular}

Data are shown as mean \pm standard deviation, median [interquartile range], or $\mathrm{n}(\%)$. 
Table 4

Chest Radiography, Pulmonary Function Testing, Arterial Blood Gas Results, and Abdominal Imaging

\begin{tabular}{|c|c|c|c|c|}
\hline Variable & $\mathbf{N}$ & Cases & Controls & $P$ Value \\
\hline \multicolumn{5}{|l|}{ Chest radiography } \\
\hline Cardiomegaly & 167 & $14(45 \%)$ & $7(5 \%)$ & $<0.001$ \\
\hline Large pulmonary arteries & 167 & $13(42 \%)$ & $1(1 \%)$ & $<0.001$ \\
\hline Interstitial lung disease & 167 & 0 & $4(3 \%)$ & 1.0 \\
\hline Hyperinflation & 167 & 0 & $1(1 \%)$ & 1.0 \\
\hline Pleural effusion & 167 & $2(6 \%)$ & $13(10 \%)$ & 0.74 \\
\hline \multicolumn{5}{|l|}{ Pulmonary function testing } \\
\hline FVC, $\%$ predicted & 162 & $85 \pm 16$ & $88 \pm 15$ & 0.38 \\
\hline FEV1, \% predicted & 162 & $83 \pm 15$ & $88 \pm 14$ & 0.14 \\
\hline FEV1/FVC & 162 & $0.77 \pm 0.07$ & $0.78 \pm 0.06$ & 0.54 \\
\hline $\mathrm{DLCO}_{\text {corr }}, \%$ predicted & 153 & $53 \pm 11$ & $62 \pm 15$ & 0.009 \\
\hline \multicolumn{5}{|l|}{ Arterial blood gas } \\
\hline $\mathrm{pH}$ & 147 & $7.46 \pm 0.03$ & $7.43 \pm 0.04$ & 0.009 \\
\hline $\mathrm{pCO}_{2}, \mathrm{~mm} \mathrm{Hg}$ & 147 & $32 \pm 4$ & $35 \pm 5$ & 0.02 \\
\hline $\mathrm{pO}_{2}, \mathrm{~mm} \mathrm{Hg}$ & 147 & $76 \pm 16$ & $87 \pm 15$ & 0.006 \\
\hline Alveolar-arterial oxygen gradient, $\mathrm{mm} \mathrm{Hg}$ & 147 & $29[14-41]$ & $13[6-20]$ & 0.007 \\
\hline \multicolumn{5}{|l|}{ Abdominal imaging } \\
\hline Splenomegaly & 163 & $20(80 \%)$ & $103(75 \%)$ & 0.57 \\
\hline Ascites & 173 & $4(15 \%)$ & $66(48 \%)$ & 0.002 \\
\hline Portal vein thrombosis & 174 & $1(4 \%)$ & $7(5 \%)$ & 1.0 \\
\hline
\end{tabular}

Data are shown as mean \pm standard deviation, median [interquartile range], or n (\%). Abbreviations: FVC, forced vital capacity; FEV1, forced

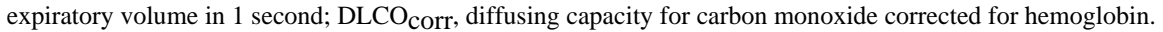


Table 5

Echocardiography Results

\begin{tabular}{lcccc}
\hline Variable & N & Cases & Controls & $P$ Value \\
\hline Right atrial dilation & 162 & $24(77 \%)$ & 0 & $<0.001$ \\
Right ventricular dilation & 167 & $28(82 \%)$ & 0 & $<0.001$ \\
Right ventricular hypertrophy & 166 & $13(41 \%)$ & 0 & $<0.001$ \\
Right ventricular dysfunction & 167 & $20(61 \%)$ & 0 & $<0.001$ \\
Paradoxical septal motion & 152 & $7(23 \%)$ & 0 & $<0.001$ \\
Tricuspid regurgitation & 166 & $31(97 \%)$ & $111(83 \%)$ & 0.049 \\
Estimated right ventricular systolic pressure, mm Hg & 91 & $77 \pm 25$ & $30 \pm 5$ & $<0.001$ \\
Pulmonic regurgitation & 129 & $23(82 \%)$ & $38(38 \%)$ & $<0.001$ \\
Left atrial size, cm & 137 & $4.1[3.5-5.5]$ & $4[3.5-4.3]$ & 0.16 \\
Left ventricular hypertrophy & 173 & $11(32 \%)$ & $25(18 \%)$ & 0.06 \\
Pericardial effusion & 166 & $7(22 \%)$ & $8(6 \%)$ & 0.011 \\
Shunting & 144 & & & 0.02 \\
$\quad$ None & & $13(57 \%)$ & $45(37 \%)$ & \\
Intrapulmonary & & $7(30 \%)$ & $68(56 \%)$ & \\
Intracardiac & & $2(9 \%)$ & $8(7 \%)$ & \\
$\quad$ Indeterminate & & $1(4 \%)$ & 0 & \\
\hline
\end{tabular}

Data are shown as mean \pm standard deviation, median [interquartile range], or $\mathrm{n}(\%)$. 
Table 6

Multivariate Logistic Regression

\begin{tabular}{lccc}
\hline Variable & OR & 95\% CI & $\boldsymbol{P}$ Value \\
\hline Female gender & 2.90 & $1.20-7.01$ & 0.018 \\
Autoimmune hepatitis & 4.02 & $1.14-14.23$ & 0.031 \\
Hepatitis C infection & 0.24 & $0.09-0.65$ & 0.005 \\
\hline
\end{tabular}

